\title{
E-COLLABORATION ARCHITECTURE FOR CUSTOMER-DRIVEN BUSINESS PROCESSES IN INTER-ORGANIZATIONAL SCENARIOS
}

Otmar Adam, Pavlina Chikova, Anja Hofer, Dominik Vanderhaeghen and Sven Zang

Institute for Information Systems (IWi) at the German Research Center for Artificial Intelligence (DFKI), Saarbruecken, Germany

\begin{abstract}
Heterogeneous customer requirements in combination with technological improvements enable new or improved customer-driven business processes. The management of such processes requires a deep but flexible integration of enterprises. In this context new forms of cooperation like E-Collaboration, describing the efficient and effective collaboration of participants in a valueadded network, arise. In order to manage customer-driven business processes across such networks, existing concepts for business process management need to be adapted and extended. In this paper an E-Collaboration architecture is presented, that shows how cross-enterprise, customer-driven processes can be planned, implemented and controlled. The architecture is based on the differentiation of global and local knowledge in the widely used Architecture for Integrated Information Systems (ARIS), developed at the IWi. Another important building block is the life-cycle-model that serves as a guideline for the process-oriented creation and operation of collaborations towards a common customer-driven production and bundling of goods and services.
\end{abstract}

Key words: E-Collaboration, Customer-Driven Process Management, Inter-Organizational Business Processes, Architecture, Process-Oriented Life-Cycle

\section{INTRODUCTION}

The growing importance of cooperation is a result of globalization in combination with the disappearance of political borders, technological advances caused mainly by the Internet as well as the alignment of business 
processes with customer needs (Naisbitt, 1986). Today the customer's position has significantly changed. Differentiation features as innovation level and additional benefits determine increasingly the purchase decision. As a consequence the markets have been turned into customer markets, on which products and services are aligned according to customer needs. Customers are being actively involved in business processes and have strong influence on which products, at which time, for which price and in which quality are produced. In this context customer-driven business processes realize the so called end-to-end-business. That means that customers do not have to combine anymore the offers of different enterprises, but that relevant enterprises rather cooperate in order to meet customer demands by providing a complete solution (Scheer, Grieble and Zang, 2003; Röhricht and Schlögel, 2001).

The borderless enterprise has been the subject of scientific discussion for years, as an organizational structure able to fulfill end-to-end requirements (Kanter, 1991; Mertens and Faisst, 1995; Picot, Wigand and Reichwald, 1997). Today new technologies based on public networks and open standards serve as enablers for effective cooperation. Therefore enterprises have the opportunity to build up new forms of cooperation characterized by a flexible and low-cost infrastructure in order to be permanently successful in largely saturated markets. The collaborative production of goods and services has been established as a crucial factor in the consciousness of economic entities. The opening of an organization's borders is no longer regarded as a necessary evil, but rather as an opportunity with strategic importance (Kanter, 1991).

Current approaches addressing solutions to specific problems of dynamically interacting organizations are summarized under the term "Business Integration"; the field of investigation is referred to as "Electronic Collaboration (E-Collaboration)" (Scheer et al., 2002). E-Collaboration describes the Internet-based collaboration of all participants in a value-added network (Scheer, Grieble and Zang, 2003). It allows a comprehensive information exchange not only between employees but also between departments and even between enterprises and encourages creative cooperation at all levels. As first case-studies show, the increase in addedvalue is out of proportion to the amount of participants in the network (Schubert, Wölfle and Dettling, 2003). Unlike former concepts, as e.g. EProcurement, which focused only on small parts of the value chain, ECollaboration incorporates all stages of added value and customer-driven business processes. While the technological implementation (Linthicum, 2003) on the one hand and the life-cycle of cooperation (Liebhart, 2002) on the other hand have already been intensively researched, too little 
consideration has been given to interconnecting business management and technological concepts. A rethinking from the pure technology driven implementation or profit-driven business model discussion to an integrated view that spans from the conceptual level to the system blueprint is needed.

For a detailed and systematic analysis and redesign of interorganizational processes enterprises need an architecture that offers a set of integrated methods from the business concept level up to the implementation into ICT-systems. The appropriate graphic representation of these contents and user-friendly, intuitive tools that ensure the flawless connection of the different levels is of great importance in order to support the exchange of ideas and the reconciliation of interests between the different recipients within the network.

For these purposes a proposal for Architecture for E-Collaboration enabling customer-driven business processes in value-added networks is developed in this article.

\section{E-COLLABORATION ARCHITECTURE}

Compared to traditional business processes the complexity of interorganizational customer-driven processes has raised considerably as a result of the changing customer requirements, the numerous possibilities of interactions as well as the strategic, structural and cultural differences between partners and customers. Coordinating business partners turns out to be more difficult, especially because of the differing objectives and the lack of inherent organizational arrangements and behavior regulations as they exist within an enterprise (Scheer, Beinhauer and Habermann, 2000). The allocation of resources of the business partners, the determination of responsibilities for material and financial exchange relationships, as well as the information and data exchange over interfaces have to be planned, arranged and "lived" together. Thus the demands imposed to CustomerDriven Process Management concepts increase.

Existing Business Process Management methods and phase models are used as a foundation in the architecture presented here, which are adapted to the specifications of collaborative scenarios related to customer-centric business processes. Especially because of its completeness of vision and its proven practicability both in the scientific and the economic context the "ARIS House" (Scheer, 2002) is accepted as a generic framework for business process management and serves as a basis for further considerations. The ARIS House describes a business process, assigning equal importance to the questions of organization, functions, outputs and the 
required data. First, it isolates these questions for separate treatment, in order to reduce the complexity of the field of description, but then all the relationships are reintegrated using the Control View introduced for this purpose.

The E-Collaboration Architecture is presented here in a three-tier framework that is connected through control loops, following the concept of business process excellence of Scheer (Scheer and Borowsky, 1999), which consists of a model to track a complete life-cycle of business process management, including modelling, real-time control and monitoring of business processes. The first layer focuses on the E-Collaboration strategy. At the centre of the second layer, the "E-Collaboration Process Engineering", there are design, optimization and controlling of both enterprise spanning and internal customer-driven processes. The third layer, "E-Collaboration Process Execution", deals with the (operational) implementation of customer-driven business processes in value-added networks as well as their support through information and communication technologies. The structure of the layer model is shown in Figure 1.

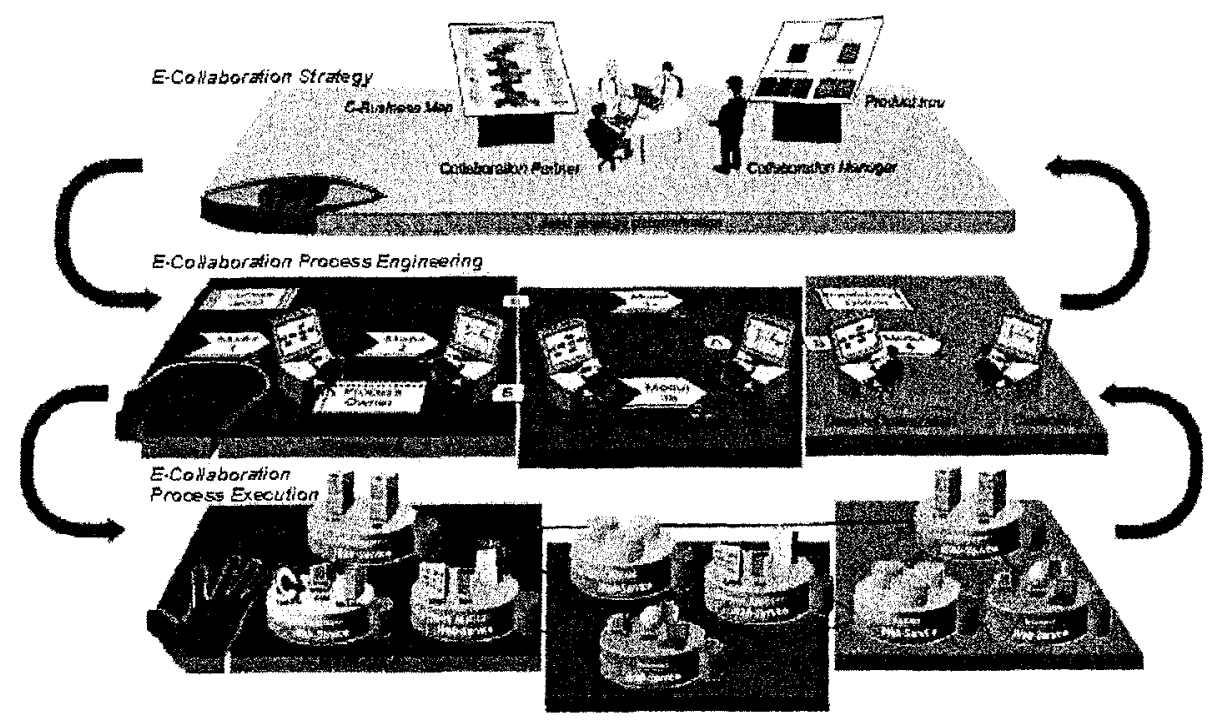

Figure 1. E-Collaboration architecture

\subsection{Views on business process models}

As described above, the framework is based on the ARIS House and divides it into a vertical axis of global knowledge of all collaboration partners and a horizontal axis of local knowledge of the single participants 
(cf. Figure 2). The organization view and the output view are global knowledge because a goal-oriented collaboration is impossible without them.

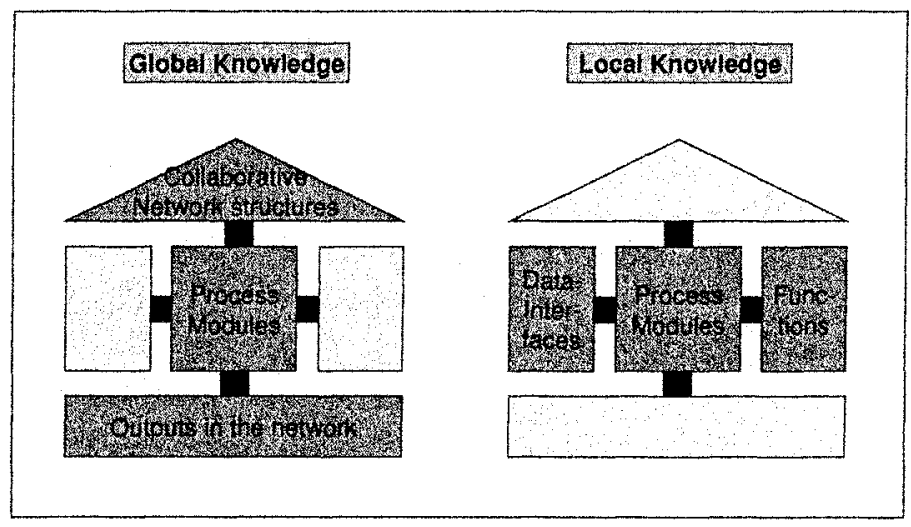

Figure 2. Global and local knowledge in value-added networks

At the time the interaction occurs between two partners, local knowledge is shared (bilaterally) between the partners, i.e. additional information, like data structures and semantics, are exchanged. Updates of the local knowledge do not influence the network as network knowledge has to be available for all partners. Changes in the global network knowledge and as a consequence changes in the output and organization view have to be accessible to all partners immediately, for example if a company leaves the network or if a product or service is no longer available within the network.

Global and local knowledge merge gradually in the step-by-step development of E-Collaboration process engineering. Following the distinction between global and local knowledge, a language is needed for the exchange of these knowledge fragments. Because the necessary detail functions and data schemes of the respective enterprise are determined in the data and the function view, these are treated from a micro perspective. They are characterized by an intensive internal interdependence, whereas externally a standardized encapsulation has to be provided. Interfaces of the data and function views to other network participants become visible in the process view in form of attribute correlations to process modules and concern the technological field of the cooperation during the realization much more intensely than the conceptual one.

This technique enables the generation of public (visible to network partners) and private (enterprise-internal) views and levels of detail for management, process owner and IT-experts out of an E-Collaboration model. 


\section{$2.2 \quad$ E-Collaboration Strategy}

Before using the architecture there is an awareness of one or more enterprises that they can profit by collaboration with complementary core competence partners. Afterwards, in the formation phase, mostly referred to initiation and agreement of the enterprise network, the collaboration partners are determined by the shared goals of the collaboration and the aspired winwin situation of all partners. The decision if and with which enterprises an ECollaboration scenario should be implemented is taken by every single enterprise individually and rationally; for this reason it depends highly on the expected economical profit of the individual partner. In the next step, the joint aims of the collaboration have to be defined as synthesis of the individual aims.

Enterprise spanning business processes are not planned in detail at the strategic level but designed as concentrated, high-level process modules related primarily to customer needs and requirements. Thus, they combine the public knowledge about the collaborative processes that is shared by all participants. Business process models for e-collaborative scenarios at the strategic level no longer act on the assumption of a chronological view of the process alone, but more on a role-based, customer-driven process model to discover new value-added potentials. To facilitate the collaborative customer service or product delivery, graphical methods, like product models, are also used at this stage for the determination of a common service or product bundle. They simplify and put the often implicit objectives into concrete terms. In addition to the characteristic features of a customer service or a product over its entire life-cycle, the organizational units participating in the production are contained in a product model (Genderka, 1995). By means of product trees enterprises can conceal detailed service descriptions in an internal view that puts special focus on the organizational aspects of the product offered by the partners. In an external view they just provide the information required for the configuration of the common service bundle in the form of product bundle models (Scheer, Herrmann and Klein, 2004). Regarding customer services, the strategic layer has to be extended, whereas there will be initialized not only service models but also directives and phases for providing services, in which the customer himself is involved.

The question about the core competences in the enterprises is directly associated with the question which customer-driven processes remain in the enterprise and which are supposed to be assigned to partner enterprises or collaboratively operated (Jost and Scheer, 2002). This decision again has direct effects on the IT-systems used, e.g. whether a portal is supposed to be implemented or the participation in an electronic marketplace is sought. E- 
Collaboration strategic and technical problems cannot be considered independently from each other; therefore the IT-architecture is already initialized.

As the basic parameters of the collaboration are determined on the first layer the procedures and the interactions are planned in more detail at the engineering layer.

\section{$2.3 \quad$ E-Collaboration Process Engineering}

On this layer each partner considers their part in the inter-enterprise customer-driven process. Each party models its own internal processes. The event-driven process chain (EPC) (Keller, Nüttgens and Scheer, 1992) - as a widely accepted method for process modelling in research and in practice (Davis, 2001) is used for the design of the process flow within an enterprise (local view).

The global view on the collaborative customer-driven process is generated in order to manage the common processes and to reduce the complexity of integrating the participating organizational units into one virtual unit. In doing so it is important that the partners provide access to all relevant information described as global knowledge beforehand and at the same time are able to hide their business secret. Both aims are achieved by enhancing the EPC with a new construct, the process module (Grieble, Klein and Scheer, 2002). It serves as an abstraction for more detailed subprocesses that contain the local knowledge and thus encapsulates crucial process information.

To generate a public view the ARIS House was expanded respectively the EPC had to be enhanced by a new construct "interface", that stands for the interfaces that link private process models within the collaborative customer-oriented scenario.

For the collaborating partners only the data at the interfaces, that is the input respectively output data of the single process modules (resp. EPC), are relevant for the realization of the collaboration. Thus it is guaranteed that the enterprise-owned EPC is only visible internally. Fuelled by the global need for organizational and output information, parts of the local business process models can then be visualized by an appropriate graphical method in order to gain knowledge of the common customer-driven processes and to reduce the complexity of integrating the participating organizational units into one virtual unit.

The collaboration partners have to continuously compare the result of the implementation with their customer-oriented goals and adjust deviations. Hitherto the management has obtained its knowledge about the company's 
success from figures of the past, e.g. cash-flow, trading volume or profit made. The causes for fluctuations, requiring immediate counter measures, are not discernible. Until the problem is recognized, valuable time has elapsed. Therefore new measurement categories which allow a reliable and contemporary evaluation of the process efficiency are required. The information needed cannot be extracted from the record and transaction oriented applications alone. Key performance-indicators must be defined based on records, log-files, time stamps etc. These can be measured and analyzed by means of intelligent tools (Jost and Scheer, 2002).

The controlling function is a must when there is a high degree of uncertainty as with E-Collaboration projects. The management can permanently control the implementation of the strategic collaboration configuration and promptly evaluate whether the expected value-added potentials and customer-oriented aims have been reached.

\section{$2.4 \quad$ E-Collaboration Process Execution}

Instead of closed systems that have been used so far, E-Collaboration requires the integration of different applications. Component based architectures that are process-driven and rely on fully developed standards and interfaces can be seen as a state-of-the-art approach to overcome these problems (McMichael, 2003).

The term "process-driven" emphasizes the importance of the process models created on the preliminary layer. At the execution layer these models are used for process orchestration. Orchestration in this context describes the composition of business objects in a process flow. In detail it defines the complex interaction between business objects, including the business logic and execution order of the interactions. Without orchestrating business objects the overall context between the single process steps would be lost.

Collaboration partners must access data and applications in an easy and secure way. Standardized mark-up languages for exchanged documents like the Extensible Markup Language (XML) are designed for this purpose. But the meaning of mark-up tags, e.g. data fields in orders and bills, varies from one enterprise to another. There are a lot of promising efforts for standardization, but there is not one common standard.

With the use of XML the technological basis for interoperability has been established, the interoperability between the semantic business process definitions is however still missing. Efforts like BPMI's Business Process Modelling Language (BPML) promise standardization for the management of inter-organizational business processes that involve different applications, departments and business partners (Smith and Fingar, 2003). This standard, 
which is based on XML, complements existing B2B protocols like RosettaNet, Biz-Talk and ebXML. On the one hand, BPML acts as an intermediary between business process modelling tools and IT. On the other hand, BPML enables the interoperability between modelling tools. Furthermore, a wide acceptance of the Business Process Execution Language for Web Services (BPEL4WS) by BEA, IBM, and Microsoft as well as the newly finalized specification of the Web Services Choreography Interface (WSCI) mainly driven by BEA, Intalio, SAP and Sun show the importance of such standardization efforts for interoperability (Shapiro, 2001). While BPML is seen as more conceptually-oriented, the latter two focus on the transformation into the system-level by orchestrating web services.

For the computer supported activity coordination in enterprise networks an information system is required that supports this two step coordination. In a repository, which is logically centralized but can be physically distributed across the enterprise network, the global knowledge is stored. Especially data about the possible participants of coordinated or orchestrated output delivery, characteristics of their products and collaborative processes are stored there. The repository is similar to the idea of an UDDI repository for the retrieval of web services (Homan, Kalavagunta and Klima, 2002), but enriched with business logic and information about the conduct of business processes.

\section{E-COLLABORATION LIFE-CYCLE}

The life-cycle-model presented in this section serves as a manual for the process-oriented setting-up and operation of enterprise collaborations towards a common customer-driven production and bundling of goods and services. Using a consistent phase model and standardized modelling methods increases transparency and structuring of collaborations and creates a basis for communication between participants, including management that lays down strategies, process-owners in the departments and IT-experts that integrate the different application systems. Despite the increased complexity of a network process in comparison to internal processes, those involved have to adapt to constantly occurring changes in a fast and flexible way.

The presented life-cycle-model is a fusion of classic phase-models of business process transformation into IT with life-cycle-models of virtual enterprises. The resulting dynamic model is consistent with the structureoriented architecture for E-Collaboration and follows the represented classification of the view concept into global and local knowledge. It is 
aimed to support E-Collaboration through the appropriate use of IT with the simultaneous improvement of inter-organizational and customer-driven processes.

Protecting internal know-how is of paramount importance to the network participants, even though the business process knowledge has to be used jointly. Following the view concept presented in paragraph 2.1 , this implies that the life-cycle alternates between phases that focus on global and on local issues in order to reach a coherent solution (cf. Figure 3). In comparison to classical knowledge management models, like the one of Nonaka, the ECollaboration life-cycle considers only explicit knowledge that is already formalized (implicit knowledge is already transformed to explicit) (Nonaka and Takeuchi, 1995).

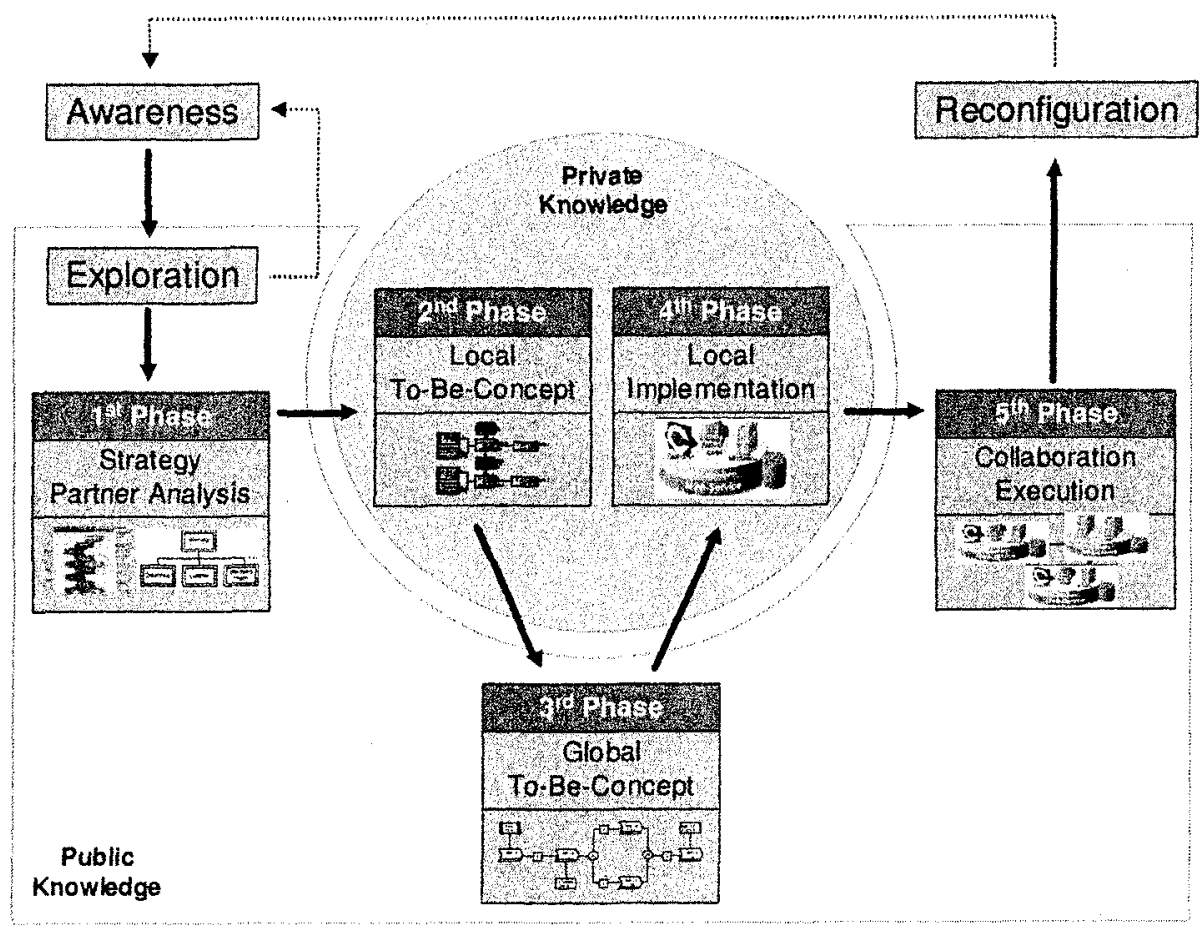

Figure 3. E-Collaboration life-cycle

Awareness for a value-added collaboration by plugging complementary core competencies has to be established in the mind of enterprises from the very beginning of the focused core-phase-model. This awareness can be initiated by a special demand, e.g. an enterprise might be confronted by a consumer order which cannot be fulfilled by the enterprise itself. 
After partner-choice has succeeded, the first phase of the collaboration, the so-called "Strategy Partner Analysis“, can start. Collaboration is initiated for all participants under the special consideration of common aims and a strived win-win situation. Thus individual aims are integrated into a common strategy - for instance by creating a common service tree, in which creation the customer is also involved. The next step is the as-is analysis concerning collaboration partners and possible value-added modules. At this strategic level the question "who delivers what?" but not "how?" is answered. Partner analysis provides models of the organization view. The structure of new collaborative products is used, for instance, for the design of e-collaboration scenario diagrams. The second phase, so called "Local To-Be-Concept", concerns the comparison of an existing or a new (local) as-is model and the (global) to-be concepts. According to predefined values about collective service creation, intra-organizational business processes can be derived. From process modelling and optimization over process controlling to execution affected processes were aligned to requirements of the collaborative customer-centric scenario predefined on the strategic layer. Every participant models his own internal processes by the use of standardized methods of business process management, e.g. the EPC. Every partner declares the process parts as public or private by defining particular attributes to model units. A process management software tool has to be extended to the particular attributes and the possibility to illustrate internal and external views. In the third phase "Global To-Be-Concept" coordinated public parts are spread over the network, establishing a common to-be concept. Every partner is able to connect his own private model with every other public process models. A virtual customer-driven process chain of the whole collaboration is designed. Therefore a common representation of process models is necessary. The Business Process Modelling Language (BPML) can be seen as an appropriate tool to enable such a data exchange. Furthermore the semantic combination of models is necessary. As long as ontology-based approaches do not reach a productive state, this process remains a manual one. During the second and third phase methods and tools from the collaborative, technical layer of the framework are used. The integrated collaborative business process model enables all partners to configure their application systems locally in a fourth phase called "Local Implementation". Reference systems for interfaces are made available by interface definitions of the common to-be concept. Now every partner is prepared for the execution of interactions within the collaborative framework. That is the transition to the fifth phase called "Collaboration Execution". Based on a bilateral base, interacting information systems are able to communicate by using the standardized protocols and interfaces. The 
concrete transaction is arranged and executed. The aim of this phase is to support collaboration through the appropriate use of ICT. That requires primarily the configuration of interfaces and the implementation of interorganizational workflows; at the same time the permanent monitoring and adoption of the collaboration, based on business ratio defined in the conception phase, must be guaranteed (Scheer, Grieble and Zang, 2003). After the transaction completion of a cooperation project, the consortium can be redesigned and reconfigured by demand regarding newly developed or modified customer requirements. The life-cycle goes back to its initial point called "Awareness", this time for a change within the collaboration instead of a new establishment.

In order to automate inter-organizational processes, the conceptual models are transformed into formal models that are used as configuration data for the orchestration of business objects. The applications of the partners have to communicate bilaterally to negotiate the interface specifications based on the formal models defined in the repository. Local knowledge is generated by this negotiation for a certain situation. After this collaboration task has ended no updates of configuration changes etc. are reported to any other party except at the time when a new direct interaction occurs. In this context multi-agent systems offer a solution to achieve an automated or at least semi-automated interface-configuration (Blake, 2003; Denti, Ricci and Rubino, 2003).

\section{CONCLUSIONS AND REALIZATION IN RESEARCH PROJECTS}

The vision of this paper is to develop an architecture and a life-cyclemodel that provides a generic solution concept, which transfers business recommendations into ICT-solutions based on a holistic customer-driven process management approach. The foundation stone is laid as the varied methods presented in the paper clearly show.

The described conceptual design of inter-enterprise and customer-driven business processes is currently elaborated in the research project "Architecture for Collaborative Scenarios (ArKoS)", funded by the German Federal Ministry of Education and Research (BMBF). As a proof of concept the presented architecture and methods will be implemented in a software prototype and will be used in real-life showcases (Zang, Hofer and Adam, 2004).

ArKoS is one of the projects in a research effort conducted by the Institute for Information Systems to improve inter-organizational business 
process management. In doing so the project reverts e.g. to the results of the successfully accomplished project InfoCitizen (Adam, Werth and Zangl, 2003). This project, funded by the European Commission under the 5th Research Framework Program, aimed at creating a pan-European Information Architecture for European Public Administrations (EPA) as well as at developing specific information technology that supports this architecture and ensures a seamless information exchange between public administrations on a pan-European level. Moreover, with this solution the EPAs have been enabled to provide transparent and integrated public services for their customers, i.e. citizens and businesses. Eleven organizations within five different EU-countries (Germany, Greece, Italy, Portugal, and Spain) worked together for two years to succeed in the challenge of pan-European interoperability. A prototype of an agent-based interoperability platform with a service repository was developed. The business processes are stored in an XML-representation and the agent platform dynamically invokes the service offers which are implemented as distributed web services.

On this basis a broad and intense dissemination and deployment impact is conducted. The generic methods developed will enable enterprises in the construction industry to seamlessly integrate partners, building owners and subcontractors in collaboration scenarios on the technology but especially on the conceptual level. Each user will experience intuitively understandable business process design, planning and control so that cooperation procedures will be very clear. User-specific views on business process models will enable new user groups to use business process models. Moreover ICT can actively support customer-driven process management by checking, verifying or even automatically negotiating consistency and interoperability of models.

\section{REFERENCES}

Adam, O., Werth, D., and Zangl, F., 2003, Conceiving and Implementing Pan-European Integrated Public Services, in: Electronic Government, Second International Conference, EGOV 2003, Prague, Czech Republic, September 1-5, 2003, Proceedings, R. Traunmüller, ed., Springer, Berlin, pp. 135-138.

Blake, M. B., 2003, Coordinating Multiple Agents for Workflow-oriented Process Orchestration (June 29, 2004); http://www.cs.georgetown.edu/ blakeb/pubs/blake_ISEB 2003.pdf.

Davis, R., 2001, Business Process Modelling with ARIS: A Practical Guide, Springer, London et al. 
Denti, E., Ricci, A., and Rubino, R., 2003, Integrating and Orchestrating Services upon a MAS Coordination Infrastructure, (June 3, 2004); http://www.ai.univie.ac.at/ paolo/ conf/ESAW03/preproc/E0011.pdf.

Genderka, M., 1995, Objektorientierte Methode zur Entwicklung von Produktmodellen als Basis integrierter Ingenieursysteme, Shaker, Aachen.

Grieble, O., Klein, R., and Scheer, A.-W., 2002, Modellbasiertes Dienstleistungsmanagement, in: Veröffentlichungen des Instituts für Wirtschaftsinformatik, A.-W. Scheer, ed., No. 171, Universität des Saarlandes, Saarbrücken.

Homan, D., Kalavagunta, S., and Klima, C., 2002, Web Services and Integration, InformationWeek, (911):65-70.

Jost, W., and Scheer, A.-W., 2002, Geschäftsprozessmanagement: Kernaufgabe einer jeden Unternehmensorganisation, in: ARIS in der Praxis: Gestaltung, Implementierung und Optimierung von Geschäftsprozessen, W. Jost, and A.-W. Scheer, ed., Springer, Berlin et al., pp. 33-44.

Kanter, R. M., 1991, Transcending Business Boundaries: 12,000 World Managers View Change, Harvard Business Review 69(3):151-164.

Keller, G., Nüttgens, M., and Scheer, A.-W., 1992, Semantische Prozessmodellierung auf Grundlage „Ereignisgesteuerter Prozessketten (EPK)“, in: Veröffentlichungen des Instituts für Wirtschaftsinformatik, A.-W. Scheer, ed., No. 89, Universität des Saarlandes, Saarbrücken.

Liebhart, U. E., 2002, Strategische Kooperationsnetzwerke: Entwicklung, Gestaltung und Steuerung, Dt. Univ.-Verl., Wiesbaden.

Linthicum, D. S., 2003, Enterprise Application Integration, 4th ed., Addison-Wesley, Boston et al.

McMichael, C., 2003, Business Process Integration May Eclipse EDI, EAI, HP Chronicle 17(6):1, 6 .

Mertens, P., and Faisst, W., 1995, Virtuelle Unternehmen - eine Organisationsstruktur für die Zukunft?, technologie \& management 44(2):61-68.

Naisbitt, J., 1986, Megatrends: Ten New Directions Transforming Our Lives, 6th ed., Warner Books, New York.

Nonaka, I., Takeuchi, H., 1995, The knowledge-creating company - How Japanese companies create the dynamics of innovation, Oxford University Press, New York.

Picot, A., Wigand, R. T., and Reichwald, R., 1997, Information, Organization and Management: Expanding Markets and Corporate Boundaries, Wiley, Chichester et al.

Röhricht, J., and Schlögel, C., 2001, cBusiness: Erfolgreiche Internetstrategien durch Collaborative Business am Beispiel my-SAP.com®, Addison-Wesley, München et al.

Scheer, A.-W., 2002, ARIS - Vom Geschäftsprozess zum Anwendungssystem, 4th ed., Springer, Berlin et al.

Scheer, A.-W. et al., 2002, Geschäftsprozessmanagement - The 2nd wave, IM Information Management \& Consulting, 17(Sonderausgabe):9-15.

Scheer, A.-W., Beinhauer, M., and Habermann, F., 2000, Integrierte E-Prozessmodellierung, Industrie Management 16(3):19-26.

Scheer, A.-W., and Borowsky, R., 1999, Supply Chain Management - die Antwort auf neue Logistikanforderungen, in: Logistik Management - Intelligente I+K Technologien, $\mathrm{H}$. Kopfer, and C. Bierwirth, ed., Springer, Berlin et al., pp. 3-14.

Scheer, A.-W., Grieble, O., and Zang, S., 2003, Collaborative Business Management, in: ECollaboration - Prozessoptimierung in der Wertschöpfungskette, W. Kersten, ed., Dt. Univ.-Verl., Wiesbaden, pp. 29-57. 
Scheer, A.-W., Herrmann, K., and Klein, R., 2004, Modellgestütztes Service Engineering Entwicklung und Design neuer Dienstleistungen, in: Dienstleistungsinnovationen: Dienstleistungsmanagement Jahrbuch 2004, M. Bruhn, and B. Stauss, ed., Gabler, Wiesbaden.

Schubert, P., Wölfle, R., and Dettling, W., 2003, E-Business-Integration: Fallstudien zur Optimierung elektronischer Geschäftsprozesse, Hanser, München et al.

Shapiro, R., 2001, A Comparison of XPDL, BPML and BPELAWS, Cape Visions, Rough Draft, pp. 1-17.

Smith, H., and Fingar, P., 2003, Business Process Management: The Third Wave, MeghanKiffer Press, Tampa.

Zang, S., Hofer, A., and Adam, O., 2004, Cross-Enterprise Business Process Management Architecture - Methods and Tools for Flexible Collaboration, in: On the Move to Meaningful Internet Systems 2004: OTM 2004 Workshops, International Workshop on Modeling Inter-Organizational Systems (MIOS) of OTM'04, Larnaca, Cyprus, R. Meersmann et al., ed., Springer, Berlin, pp. 483-494. 